I would agree with Dr Morris that freedom to prescribe more potent and expensive drugs when clinically necessary should be maintained, but suspect that if economies such as those above were standard practice the saving to the NHS would be far more than the $£ 5$ million that Dr David Owen hopes to achieve by negotiation with the drug industry. I share the hope that political limitation on prescribing will not come about, but fear that if it does the profession will have itself largely to blame. The abuse of the plethora of potent but dangerous and expensive drugs now available, in both hospital and general practice, seems to me to make it inevitable that some form of enforceable system of medical audit is already necessary.

\section{J Holdstock}

\section{Ashford Hospital}

Ashford

\section{Dangers of tinted glasses for driving}

SIR,-Surely Mr J B Davey (24 July, p 233) misses the point when he says that the drive of a car can remove his photochromic sun glasses when he drives into a dark area. Most people, myself included, who wear photochromic lens do so on prescription because we need glasses to see properly. We choose photochromic lenses because they have the advantage that we need never take the glasses off when we encounter bright sunlight, nor are we bothered with the chore of hunting for pair of clip-on sunglasses in the glove compartment, etc. However, I would echo the point that, because they do not "lighten" quickly enough in going suddenly through a tunnel, every driver who uses this type of lenses should remember to carry his regular glasses on his person, so that a quick change may be accomplished should he expect to encounter this hazard.

\section{Eugene ConNoll}

Regional Hospital,

Galway

\section{Elderly mentally ill}

SIR,-Miss Pauline Pasker and others present some interesting findings in their article, "The elderly mentally ill-whose responsibility?" (17 July, p 164), but I wonder if they were right to condemn screening methods as "costly ... and only of academic interest." The Newcastle survey, which they quote, ${ }^{1}$ reveals that about 200 in every thousand elderly people suffer from psychiatric symptoms of moderate or greater severity, while a further 170 have milder symptoms. If this represent the extent of psychogeriatric ill health in the community, then the authors' discovery of 18.2 per thousand "psychogeriatric popula tion" known to ward sisters, wardens of residential homes, and community nurses prompts the question, Who are looking after the rest?

It seems a pity that social workers' replies were not included, since they play an important part in supporting the elderly mentally ill at home both by arranging home helps, domiciliary meals, holidays, luncheon club attendance, etc, and by providing emotiona support and encouragement for the patient' community supporting network of family and friends, but even they are unlikely to account for the missing $91^{\circ}$ " of moderately disabled people. I am afraid that the great majority of sufferers are not in receipt of services from anyone. The iceberg of unknown and unmet need is, I submit, greater than that which sank the Titanic. I know that we live in difficult times, but unless we recognise the growing problem in old age of mental ill health, and in particular the insidious and damaging problem of dementia, unless we make plans now to greatly increase the amount of both domiciliary and institutional support available and implement them as soon as the financial situation eases, then the health and social services wil be guilty of a monstrous neglect.

\section{St Nicholas Hospital,}

Gosforth

${ }^{1}$ Kay, D W K, et al, British fournal of Psychiatry, 1964
110, 146.

\section{Reducing outpatient attendances}

SIR,-I agree with Mr R M Kirk's (19 June, $p$ 1521) views on the essential need to restric hospital follow-up attendances and endorse his suggestions and those of Dr A P Warin (31 July, p 299) for achieving this. In our own department I try to restrict the number of return visits in the ways they indicate. However, I believe it should be emphasised some follow-up appointments must take place if the hospital clinician is ever to observe whether an opinion given has been correct, or if advice on treatment or management has been successful. For a time the doctor with confidence in his own infallibility can perhaps assume he has been doing the right thing; but the years pass by, new measures and understandings come along continuously, and, without the opportunity to follow-up, the doctor will deprive himself of many chances to keep on learning about his subject. I would therefore plead that some return visits are essential for both the understanding of the hospital doctor and the welfare of his future patients. Perhaps in this way the follow-up constitutes a part of the fashionable medical audit.

JOHN K MORGAN

Carter Bequest Hospital

Middlesbrough

\section{Neuropathy in experimental diabetes}

SIR,-The paper by Dr J Jakobsen and Professor K Lundbaek (31 July, p 278) requires comment. The authors have claimed tha in streptozotocin-induced diabetes in rats nerve fibre size is reduced when examined after four weeks and that the reduction affects the axons to a greater extent than the myelin sheaths. They suggest that this may contribute towards the reduction in nerve conduction velocity that is known to occur in experimenta diabetes. The authors have based their conclusion on a comparison with age-matched nondiabetic control animals. This may lead to a fallacious interpretation. Fibre size is known to increase progressively in rats, at least throughout the first year of life. Diabetic rats lose weight and show retarded skeletal growth. It is possible that the normal maturation of nerve fibre size fails to occur. Thus the difference in fibre size found by Jakobsen and
Lundbaek may be due to a failure of growth in the diabetic animals as compared with the controls rather than representing a true reduction in fibre diameter.

Recently we $\mathrm{w}^{1}$ have made observations on nerve fibre size in rats employing consecutive observations on the same animals before and after the induction of diabetes with streptozotocin. Fibre size was measured in nine rat in the tibial nerve at biopsy immediately before induction of diabetes and in the contralateral nerve removed five weeks later. The prediabetic values for maximal and average total fibre diameter were $11.9 \pm 0.68$ and $6 \cdot 5 \pm 0.28: u \mathrm{~m}$ respectively. The corresponding values after five weeks of diabetes (blood glucose levels $17 \cdot 8-32 \cdot 2 \mathrm{mmol} / 1^{-1}$ ) were $12 \cdot 1$ t 0.34 and $6.6 \pm 0.32: \mathrm{m}$. Although the latter are slightly greater, the prediabetic and post diabetic values do not differ significantly. We have therefore failed to demonstrate any reduction in fibre size.

Serial observations on nerve conduction velocity in experimental diabetes in rats: show that velocity falls within a week and remains reduced. Our previous observations: have established that the peripheral nerves show no evidence of segmental demyelination or detectable ultrastructural change. We therefore consider that a metabolic basis for the electrophysiological changes is more probable than a structural alteration discernible by curren morphological techniques.

P K THOMAS A K Sharma

Department of Neurology,

Royal Free Hospital

\section{Sharma, A K, et al, to be published. \\ Clectroencephalography and Clinical Neurophysiology, 1973, 35, 125. \\ harma, A K, and Thomas, P K, fournal of the Neurological Sciences, 1974, 23,}

\section{Requests for references}

SIR,-Dr T B Boulton (24 July, p 236) has voiced the disquiet felt by many consultants. All too often a request for a confidential report is accompanied by a return envelope addressed to the "district administrator" or "personnel officer" and perhaps without any "confidential" stamp. Individual administrators may feel quite sincerely that their own arrangements for receipt and custody of references is above reproach, but it is essential that the consultant who writes the testimonial should also be sure that his confidence is respected. There is otherwise a danger that such references might become stereotyped and based on factual data rather than opinions and judgments.

There seems to be one clear way to put matters right. The consultant dissatisfied with a request from a health authority should write back politely explaining the reasons why he feels unable to supply a reference. At the same time he should ascertain the name of the senior consultant in the appropriate specialty and send him a confidential and personal report by first-class mail. United action would soon reverse what is at present a deteriorating situation.

R S ATKINSON CHRISTOPHER J SPIVEY M J WATT JOHN SHELSWELL

Southend Hospital 